BMJ Open

Diabetes

Research

\& Care

\title{
Coagulopathy is a major extrapulmonary risk factor for mortality in hospitalized patients with COVID-19 with type 2 diabetes
}

Xiaoyan Chen, ${ }^{1}$ Ying Chen, ${ }^{2}$ Chaomin Wu, ${ }^{1,3}$ Ming Wei, ${ }^{4}$ Jie $X u,{ }^{5}$ Yen-cheng Chao, ${ }^{1}$ Juan Song, ${ }^{1}$ Dongni Hou, ${ }^{1}$ Yuye Zhang (D) , ${ }^{1}$ Chunling Du, ${ }^{3}$ Xiaoying Li, ${ }^{2}$ Yuanlin Song (1) 1,3,6,7

To cite: Chen $X$, Chen $Y$, Wu C, et al. Coagulopathy is a major extrapulmonary risk factor for mortality in hospitalized patients with COVID-19 with type 2 diabetes. BMJ Open Diab Res Care 2020;8:e001851. doi:10.1136/ bmjdrc-2020-001851

- Supplemental material is published online only. To view, please visit the journal online (http://dx.doi.org/10.1136/ bmjdrc-2020-001851).

$\mathrm{XC}$, YChen, CW and MW contributed equally.

Received 22 August 2020 Revised 26 October 2020 Accepted 2 November 2020

Check for updates

(c) Author(s) (or their employer(s)) 2020. Re-use permitted under CC BY-NC. No commercial re-use. See rights and permissions. Published by BMJ.

For numbered affiliations see end of article.

Correspondence to Professor Yuanlin Song; ylsong70_02@163.com

\section{ABSTRACT}

Introduction To investigate the risk factors for the death in patients with COVID-19 with type 2 diabetes mellitus (T2DM).

Research design and methods We retrospectively enrolled inpatients with COVID-19 from Wuhan Jinyintan Hospital (Wuhan, China) between December 25, 2019, and March 3, 2020. The epidemiological and clinical data were compared between non-T2DM and T2DM or between survivors and non-survivors. Univariable and multivariable Cox regression analyses were used to explore the effect of T2DM and complications on in-hospital death.

Results A total of 1105 inpatients with COVID-19, 967 subjects with without T2DM ( $\mathrm{n}=522$ male, $54.0 \%$ ) and 138 subjects with pre-existing T2DM ( $\mathrm{n}=82$ male, 59.4\%) were included for baseline characteristics analyses. The complications were also markedly increased in patients with pre-existing T2DM, including acute respiratory distress syndrome (ARDS) $(48.6 \%$ vs $32.3 \%$, $\mathrm{p}<0.001)$, acute cardiac injury (ACI) $(36.2 \%$ vs $16.7 \%$, $\mathrm{p}<0.001)$, acute kidney injury (AKI) $(24.8 \%$ vs $9.5 \%$, $\mathrm{p}<0.001)$, coagulopathy $(24.8 \%$ vs $11.1 \%, p<0.001)$, and hypoproteinemia $(21.2 \%$ vs $9.4 \%, p<0.001)$. The in-hospital mortality was significantly higher in patients with pre-existing T2DM compared with those without T2DM (35.3\% vs $17.4 \%, \mathrm{p}<0.001)$. Moreover, in hospitalized patients with COVID-19 with T2DM, ARDS and coagulopathy were the main causes of mortality, with an HR of 7.96 (95\% Cl 2.25 to $28.24, p=0.001)$ for ARDS and an HR of 2.37 (95\% Cl 1.08 to $5.21, \mathrm{p}=0.032)$ for coagulopathy. This was different from inpatients with COVID-19 without T2DM, in whom ARDS and cardiac injury were the main causes of mortality, with an HR of 12.18 (95\% Cl 5.74 to $25.89, p<0.001)$ for ARDS and an HR of $4.42(95 \% \mathrm{Cl} 2.73$ to $7.15, \mathrm{p}<0.001)$ for cardiac injury. Conclusions Coagulopathy was a major extrapulmonary risk factor for death in inpatients with COVID-19 with T2DM rather than $\mathrm{ACl}$ and $\mathrm{AKI}$, which were well associated with mortality in inpatients with COVID-19 without T2DM.

\section{INTRODUCTION}

COVID-19 has become a global pandemic and has resulted in hundreds of thousands of death since its outbreak in December

\section{Significance of this study}

What is already known about this subject?

- Mortality is much greater in patients with COVID-19 with type 2 diabetes mellitus (T2DM).

What are the new findings?

- Coagulopathy was a major extrapulmonary risk factor for death in inpatients with COVID-19 with T2DM rather than acute cardiac injury (ACl) and acute kidney injury (AKI), which were well associated with mortality in inpatients with COVID-19 without T2DM. Patients with COVID-19 with T2DM were associated with increased risk of death, acute respiratory distress syndrome, $\mathrm{ACl}, \mathrm{AKI}$ and coagulopathy.

How might these results change the focus of research or clinical practice?

- Addressing prolonged prothrombin time/activated partial thromboplastin time can help clinicians to identify patients with T2DM with high risk of death and to take action early.

2019. ${ }^{1}$ Of note, diabetes is a major comorbidity of COVID-19 and constitutes a higher proportion of patients with severe and critically ill cases of COVID-19 than patients with mild symptoms. ${ }^{2}$ It is reported that poorly controlled blood glucose was associated markedly increased mortality in COVID-19 and pre-existing patients with diabetes. ${ }^{3}$

In patients with COVID-19, the respiratory tracts and lungs are first attacked by SARS-CoV-2 and acute respiratory distress syndrome (ARDS) rapidly develops. ${ }^{45}$ ARDS and other multiple organ injury are the major causes of death in patients with COVID-19. ${ }^{67}$ Nevertheless, in patients with COVID-19 with type 2 diabetes, the association of mortality with ARDS and other organ dysfunctions has not been well studied. In this study, we retrospectively analyzed a large group of 
hospitalized patients with COVID-19 in Wuhan, China, and revealed that type 2 diabetes increased the risk of death and multiple organ dysfunctions, including pulmonary complication (eg, ARDS) and extrapulmonary complications. Surprisingly, coagulopathy was a major extrapulmonary risk factor for death in hospitalized patients with COVID-19 with type 2 diabetes rather than acute cardiac injury (ACI) and acute kidney injury (AKI), which were well associated with mortality in hospitalized patients with COVID-19 without type 2 diabetes.

\section{METHODS}

\section{Study design and participants}

This retrospective cohort study enrolled consecutively inpatients with COVID-19 from Wuhan Jinyintan Hospital (Wuhan, China) between 25 December 2019 and 3 March 2020 (admission date). All patients who were diagnosed with COVID-19 according to WHO interim guidance ${ }^{8}$ were included. This cohort was followed up to 10 March 2020.

\section{Data collection}

All of the medical records were reviewed and extracted from electronic medical records by well-trained physicians and medical students. After removing the personal information (eg, name and identification (ID)) of the participants and assigning a deidentified patient ID, the epidemiological, clinical, laboratory, treatment, and outcome data were acquired using a standardized data collection form. All data were independently checked by two investigators and a third physician adjudicated any difference in interpretation between the two primary reviewers.

\section{Laboratory procedures}

The protocol for confirmation of SARS-CoV-2 infection has been described previously. ${ }^{9}$ Throat-swab samples were checked for SARS-CoV-2 using real-time reverse transcription PCR. The routine blood tests included complete blood count, coagulation profiles, biochemical tests (including renal and liver functions, creatine kinase, lactate dehydrogenase, and glucose), procalcitonin, interleukin-6, serum ferritin, and myocardial enzymes. Chest X-rays or CT scans were also performed for all the inpatients. The majority of the clinical data used in this study was taken at baseline unless indicated otherwise.

\section{Outcomes and definitions}

The primary endpoint of the study was all-cause death in inpatients with COVID-19. The secondary endpoints were occurrence of ARDS, ACI, acute liver injury (ALI), AKI, coagulopathy, hypoproteinemia, and secondary infection.

Fever was defined as axillary temperature of at least $37.3^{\circ} \mathrm{C}$. Pre-existing type 2 diabetes mellitus (T2DM) was designated based on the patient's medical history, which was diagnosed according to the American Diabetes Association 2010 criteria. ${ }^{10}$ Hypertension was diagnosed referring to the patient's medical history. ARDS was diagnosed following WHO interim guideline. ${ }^{8}$ Acute liver injury was defined as jaundice with total bilirubin levels of $\geq 3 \mathrm{mg} / \mathrm{dL}$ and an acute increase in alanine aminotransferase of at least fivefolds the upper limit of the normal range and/or an increase in alkaline phosphatase of at least twofolds the upper limit of the normal range. ${ }^{11}$ AKI was identified according to the Kidney Disease: Improving Global Outcomes definition. ${ }^{12}$ ACI was diagnosed when serum levels of cardiac biomarkers (high-sensitive cardiac troponin I (hs-TnI)) were above the 99th percentile the upper reference limit, regardless of new abnormalities in electrocardiography and echocardiography. ${ }^{13}$ Hypoproteinemia was defined as blood albumin levels of $\leq 25 \mathrm{~g} / \mathrm{L}$. Coagulopathy was defined as a $3 \mathrm{~s}$ extension of prothrombin time (PT) or a $5 \mathrm{~s}$ extension of activated partial thromboplastin time. ${ }^{14}$ The diagnosis of secondary infection was determined in case of the occurrence of clinical symptoms or signs of pneumonia or bacteremia and a positive culture of a new pathogen was achieved from lower respiratory tract samples (qualified sputum, endotracheal aspirate, or bronchoalveolar lavage fluid) or blood specimens after admission. ${ }^{15}$

\section{Statistical analysis}

Continuous and categorical variables were presented using mean $\pm \mathrm{SD}$ or median (IQR) and $\mathrm{n}(\%)$, respectively. Mann-Whitney U test, $\chi^{2}$ test, or Fisher's exact were used to compare differences between non-T2DM and T2DM or between survivors and non-survivors wherever appropriate. Univariable and multivariable Cox regression analyses were used to explore the risk of type 2 diabetes on in-hospital death and complications. Results were summarized as HR and 95\% CI. Our previous study and other studies have demonstrated that potential risk factors for death in patients with COVID-19, including older age, gender, comorbidities, and treatments. ${ }^{6914}$ Therefore, we adjusted age, gender, comorbidities (hypertension, chronic lung disease, chronic liver disease, chronic kidney disease, coronary heart disease, and malignant tumor), and treatments (antibiotic and antiviral therapy) in this multivariable Cox regression analyses. Moreover, we included ARDS, ACI, ALI, AKI, coagulopathy, d-dimer hypoproteinemia, secondary infection and treatments (antiplatelet and anticoagulant therapy) as the factors in other Cox regression analyses to find out which one is the major risk factor for death in patients with and without T2DM. A two-sided $p$ value less than 0.05 was considered statistically significant. All statistical analyses were performed using R V.3.6.3 (R Foundation for Statistical Computing, Vienna, Austria).

\section{RESULTS}

\section{Clinical characteristics}

A total of 1105 COVID-19 hospitalized patients, 967 subjects with non-T2DM ( $\mathrm{n}=522$ male, $54.0 \%)$ and 138 subjects with pre-existing T2DM ( $\mathrm{n}=82$ male, 59.4\%) 
Table 1 Baseline characteristics of inpatients with COVID-19 with or without pre-existing T2DM

\begin{tabular}{|c|c|c|c|c|}
\hline & $\begin{array}{l}\text { Total } \\
(\mathrm{N}=1105)\end{array}$ & $\begin{array}{l}\text { Non-T2DM } \\
(\mathrm{n}=967)\end{array}$ & $\begin{array}{l}\text { T2DM } \\
(n=138)\end{array}$ & $P$ value \\
\hline Age (years), mean $\pm S D$ & $56.3 \pm 14.5$ & $55.3 \pm 14.5$ & $63.4 \pm 12.8$ & $<0.001$ \\
\hline \multicolumn{5}{|l|}{ Gender, n (\%) } \\
\hline Male & $604(54.7)$ & $522(54.0)$ & $82(59.4)$ & 0.230 \\
\hline Female & $501(45.3)$ & $445(46.0)$ & $56(40.6)$ & \\
\hline Glycated hemoglobin* (\%) & $6.4(5.9-7.4)$ & $6.2(5.9-6.9)$ & $7.8(7.1-9.1)$ & $<0.001$ \\
\hline \multicolumn{5}{|l|}{ Comorbidities, n (\%) } \\
\hline Hypertension & $304(27.5)$ & $228(23.6)$ & $76(55.1)$ & $<0.001$ \\
\hline Coronary heart disease & $59(5.3)$ & $38(3.9)$ & $21(15.2)$ & $<0.001$ \\
\hline Chronic liver disease & $39(3.5)$ & $33(3.4)$ & $6(4.3)$ & 0.756 \\
\hline Chronic kidney disease & $20(1.8)$ & $13(1.3)$ & $7(5.1)$ & 0.006 \\
\hline Chronic lung disease $†$ & $42(3.8)$ & $35(3.6)$ & $7(5.1)$ & 0.403 \\
\hline Malignant tumor & $24(2.2)$ & $22(2.3)$ & $2(1.4)$ & 0.756 \\
\hline \multicolumn{5}{|l|}{ Signs and symptoms, n (\%) } \\
\hline Fever & $969(87.7)$ & $852(88.1)$ & $117(84.8)$ & 0.266 \\
\hline Cough & $857(77.6)$ & $750(77.6)$ & $107(77.5)$ & 0.995 \\
\hline Dyspnea & $598(54.0)$ & $515(53.3)$ & $82(59.4)$ & 0.174 \\
\hline Fatigue or myalgia & $422(38.2)$ & $374(38.7)$ & $48(34.8)$ & 0.378 \\
\hline Diarrhea & $68(6.2)$ & $61(6.3)$ & $7(5.1)$ & 0.583 \\
\hline Hemoptysis & $4(0.4)$ & $4(0.4)$ & 0 & $>0.999$ \\
\hline Headache & $60(5.4)$ & $54(5.6)$ & $6(4.3)$ & 0.549 \\
\hline Systolic blood pressure (mm Hg) & $125(115-136)$ & $125(115-136)$ & $127(115-140)$ & 0.113 \\
\hline Diastolic blood pressure $(\mathrm{mm} \mathrm{Hg})$ & $80(74-87)$ & $80 .(75-87)$ & $80(73-87)$ & 0.927 \\
\hline Respiratory rate, breaths/min & $21.0(20.0-24.0)$ & $21.0(20.0-24.0)$ & $21.0(20.0-24.7)$ & 0.361 \\
\hline Heart rate (beats/min) & $86(80-97)$ & $86(80-96)$ & $86(80-98)$ & 0.781 \\
\hline Chest imaging, $\ddagger \mathrm{n}(\%)$ & & & & 0.859 \\
\hline Unilateral infiltrate & $117(10.6)$ & $103(10.7)$ & $14(10.1)$ & \\
\hline Bilateral infiltrate & $988(89.4)$ & $864(89.3)$ & $124(89.9)$ & \\
\hline \multicolumn{5}{|l|}{ Treatment in hospital, $\mathrm{n}(\%)$} \\
\hline Antiviral§ & $580(52.5)$ & $518(53.6)$ & $62(44.9)$ & 0.057 \\
\hline Antibiotic & 1015 (91.9) & $887(91.7)$ & $128(92.8)$ & 0.680 \\
\hline Corticosteroid therapy & $334(30.2)$ & $293(30.3)$ & $41(29.7)$ & 0.888 \\
\hline Antiplatelet therapy & $37(3.3)$ & $25(2.6)$ & $12(8.7)$ & $<0.001$ \\
\hline Anticoagulant therapy & $134(12.1)$ & $112(11.6)$ & $22(15.9)$ & 0.142 \\
\hline
\end{tabular}

Data are expressed as mean \pm SD, median $(\mathrm{IQR})$, or $\mathrm{n}(\%)$.

*Initial test.

†Including chronic pulmonary diseases such as chronic obstructive pulmonary disease, asthma, chronic bronchitis, bronchiectasis, and pulmonary tuberculosis.

$\ddagger$ Chest imaging, including chest X-ray and CT scan before being hospitalized.

§Including oseltamivir, ganciclovir, lopinavir, and interferon.

T2DM, type 2 diabetes mellitus.

were included for baseline characteristics analyses (table 1). Patients with pre-existing T2DM were older $(63.40 \pm 12.80$ vs $55.30 \pm 14.50$ years, $\mathrm{p}<0.001)$ had higher glycated hemoglobin $(7.8 \%$ (IQR $7.1 \%-9.1 \%$ ) vs $6.2 \%$ (IQR 5.9\%-6.9\%), $\mathrm{p}<0.001$ ), and more comorbidities, including hypertension ( $55.1 \%$ vs $23.6 \%, \mathrm{p}<0.001)$, coronary heart disease $(15.2 \%$ vs $3.9 \%, \mathrm{p}<0.001)$, and chronic kidney disease $(5.1 \%$ vs $1.3 \%, \mathrm{p}=0.006)$. Consistent with our previous study, ${ }^{9}$ the most common symptoms were fever $(87.7 \%)$, cough $(77.6 \%)$, dyspnea $(54.0 \%)$, and fatigue or myalgia $(38.32 \%)$ in the whole cohort. There were no significant differences between inpatients with COVID-19 with pre-existing T2DM and without T2DM regarding vital signs (blood pressure, respiratory rate, 
and heart rate) and chest infiltrate. As for the in-hospital treatment, more inpatients with COVID-19 with pre-existing T2DM $(8.7 \%$ vs $2.6 \%, \mathrm{p}<0.001)$ received antiplatelet therapy compared with those without preexisting T2DM.

\section{Biochemical and cellular characteristics}

As shown in online supplemental table S1, initial laboratory findings showed that the pre-existing T2DM group had higher blood glucose $(8.70 \mathrm{mmol} / \mathrm{L}$ (IQR 6.23-13.38 $\mathrm{mmol} / \mathrm{L})$ ) than the non-T2DM group $(5.80 \mathrm{mmol} / \mathrm{L}$ (IQR 5.10-7.20 $\mathrm{mmol} / \mathrm{L})$ ), as expected. Meanwhile, patients with pre-existing T2DM had increased neutrophils $\left(4.61 \times 10^{9} / \mathrm{L}\right.$ (IQR $\left.3.21-7.49 \times 10^{9} / \mathrm{L}\right)$ vs $3.97 \times 10^{9} / \mathrm{L}$ (IQR 2.55-6.60×10 $/ \mathrm{L}$ ), p=0.011), decreased lymphocytes, including lymphocyte counts $\left(0.82 \times 10^{9} / \mathrm{L}\right.$ (IQR $\left.0.59-1.19 \times 10^{9} / \mathrm{L}\right)$ vs $1.00 \times 10^{9} / \mathrm{L}$ (IQR $0.67-1.38 \times 10^{9} /$ $\mathrm{L}), \mathrm{p}=0.001)$, CD3 $(367.00 / \mu \mathrm{L}$ (IQR 239.00-627.00/ $\mu \mathrm{L})$ vs $611.00 / \mu \mathrm{L}(\mathrm{IQR} \quad 439.50-890.25 / \mu \mathrm{L}), \mathrm{p}=0.028$ ), CD4 $(234.00 / \mu \mathrm{L}$ (IQR $166.00-359.25 / \mu \mathrm{L})$ vs $357.50 / \mu \mathrm{L}$ (IQR 234.00-566.00/ $\mu \mathrm{L}$ ), $\mathrm{p}=0.049$ ), and CD8 (115.00/ $\mu \mathrm{L}$ (IQR 77.75-154.00/ $\mu \mathrm{L}$ ) vs $234.00 / \mu \mathrm{L}$ (IQR 151.25$319.50 / \mu \mathrm{L}), \mathrm{p}=0.005)$, elevated inflammatory indices, including hypersensitive $\mathrm{C}$ reactive protein $(55.30 \mathrm{mg} / \mathrm{L}$ (IQR $15.70-129.10 \mathrm{mg} / \mathrm{L}$ ) vs $29.70 \mathrm{mg} / \mathrm{L}$ (IQR 6.50 $84.20 \mathrm{mg} / \mathrm{L}), \mathrm{p}<0.001)$ and serum ferritin (598.99 ng/ $\mathrm{mL}$ (IQR $360.07-1268.70 \mathrm{ng} / \mathrm{mL}$ ) vs $525.09 \mathrm{ng} / \mathrm{mL}$ (IQR 287.63-1036.04 ng/mL), $\mathrm{p}=0.025$ ) compared with the group without diabetes. These findings were consistent with previous study in patients with COVID-19 with T2DM. ${ }^{3}$ Consistently, dysregulated immune responses were also observed in patients with diabetes with other coronavirus infections, which revealed that diabetic mice had fewer inflammatory monocytes, macrophages and $\mathrm{CD} 4 \mathrm{~T}$ cells, which were accompanied by impaired expressions of CCL2 and CXCL10. ${ }^{16}$

Furthermore, patients with pre-existing T2DM showed impaired kidney function, measured by urea $(5.75$ $\mathrm{mmol} / \mathrm{L}$ (IQR $4.40-8.03 \mathrm{mmol} / \mathrm{L}$ ) vs $4.50 \mathrm{mmol} / \mathrm{L}$ (IQR 3.49-5.86 mmol/L), $\mathrm{p}<0.001)$, creatinine $(74.70$ $\mu \mathrm{mol} / \mathrm{L}(\mathrm{IQR} \quad 60.90-96.00 \mu \mathrm{mol} / \mathrm{L}$ ) vs $68.50 \mu \mathrm{mol} / \mathrm{L}$
(IQR 57.20-81.00 $\mu \mathrm{mol} / \mathrm{L}), \mathrm{p}<0.001$ ), and cystatin $\mathrm{C}$ (1.01 mg/L (IQR $0.85-1.48 \mathrm{mg} / \mathrm{L}$ ) vs $0.85 \mathrm{mg} / \mathrm{L}$ (IQR 0.72-1.02 mg/L), $\mathrm{p}<0.001)$, increased heart injury, indicated by hs-TnI $(9.65, \mathrm{pg} / \mathrm{mL}$ (IQR $2.90-30.90 \mathrm{pg}$ ) $\mathrm{mL}$ ) vs $3.90 \mathrm{pg} / \mathrm{mL}$ (IQR $1.40-10.23 \mathrm{pg} / \mathrm{mL}, \mathrm{p}<0.001$ ), CK-MB (15.00 U/L (IQR 10.00-20.00 U/L) vs $13.00 \mathrm{U} / \mathrm{L}$ (IQR 10.00-17.00 U/L), $\mathrm{p}=0.014$ ), and $\alpha$-hydroxybutyric dehydrogenase $(\alpha-\mathrm{HBDH}) \quad(264.00 \mathrm{U} / \mathrm{L}$ (IQR 207.00$393.75 \mathrm{U} / \mathrm{L}$ ) vs $226.00 \mathrm{U} / \mathrm{L}$ (IQR $179.00-319.00 \mathrm{U} / \mathrm{L}$ ), $\mathrm{p}<0.001)$, dysregulated coagulation defined as prolonged PT (11.60 s (IQR 10.80-12.80 s) vs $11.30 \mathrm{~s}$ (IQR 10.50$12.10 \mathrm{~s}), \mathrm{p}=0.001)$ and d-dimer $(1.17 \mu \mathrm{g} / \mathrm{mL}$ (IQR $0.55-4.22 \mu \mathrm{g} / \mathrm{mL}$ ) vs $0.73 \mu \mathrm{g} / \mathrm{mL}$ (IQR $0.42-1.72 \mu \mathrm{g}$ / $\mathrm{mL}), \mathrm{p}<0.001)$, and higher lactic dehydrogenase, lactate dehydrogenase (LDH) (329.00 U/L (IQR 236.00-451.50 $\mathrm{U} / \mathrm{L}$ ) vs $278.50 \mathrm{U} / \mathrm{L}$ (IQR 221.00-379.25 U/L), $\mathrm{p}=0.001$ ), accompanied by lower albumin $(30.40 \mathrm{~g} / \mathrm{L}$ (IQR 27.00$34.00 \mathrm{~g} / \mathrm{L})$ vs $32.10 \mathrm{~g} / \mathrm{L}(29.20-35.40 \mathrm{~g} / \mathrm{L}), \mathrm{p}<0.001)$, prealbumin $(121.00 \mathrm{mg} / \mathrm{L}$ (IQR $85.00-156.00 \mathrm{mg} / \mathrm{L})$ vs $131.00 \mathrm{mg} / \mathrm{L}$ (IQR 88.00-189.50 mg/L), p=0.014), and low-density lipoprotein $(329.00 \mathrm{mmol} / \mathrm{L}$ (IQR 236.00 $451.50 \mathrm{mmol} / \mathrm{L}$ ) vs $278.50 \mathrm{mmol} / \mathrm{L}$ (IQR 221.00-379.25 $\mathrm{mmol} / \mathrm{L}), \mathrm{p}<0.001$ ), compared with the group without diabetes. These results indicated that both a dysregulated immune response and multiple organ dysfunctions associated with pre-existing T2DM were likely responsible for poor outcomes of COVID-19 inpatients.

\section{Primary and secondary outcomes}

Until March 10, 2020, of 1105 inpatients with COVID19, 888 patients with COVID-19 (80.4\%) were discharged from the hospital, 379 (34.3\%) patients developed ARDS, $198(19.1 \%)$ ACI, 122 (11.4\%) AKI, 133 (12.8\%) coagulopathy, $118(10.9 \%)$ hypoproteinemia, 107 (10.5\%) secondary infection, 10 (1.0\%) ALI, and 217 (19.6\%) patients died (table 2). The complications were also markedly increased in patients with pre-existing T2DM, including ARDS (48.6\% vs $32.3 \%$, p $<0.001)$, ACI (36.2\% vs $16.7 \%, \mathrm{p}<0.001)$, AKI ( $24.8 \%$ vs $9.5 \%, \mathrm{p}<0.001)$, coagulopathy (24.8\% vs $11.1 \%, \mathrm{p}<0.001)$, and hypoproteinemia $(21.2 \%$ vs $9.4 \%, \mathrm{p}<0.001)$. The in-hospital mortality

Table 2 Outcome events in inpatients with COVID-19 with or without pre-existing T2DM

\begin{tabular}{lllll}
\hline & $\begin{array}{l}\text { Total } \\
(\mathbf{N = 1 1 0 5 )}\end{array}$ & $\begin{array}{l}\text { Non-T2DM } \\
\mathbf{( n = 9 6 7 )}\end{array}$ & $\begin{array}{l}\text { T2DM } \\
(\mathbf{n = 1 3 8 )}\end{array}$ & P value \\
\hline Death, $\mathrm{n}(\%)$ & $217(19.6)$ & $168(17.4)$ & $49(35.5)$ & $<0.001$ \\
ARDS, $\mathrm{n}(\%)$ & $379(34.3)$ & $312(32.3)$ & $67(48.6)$ & $<0.001$ \\
\hline Acute cardiac injury, $\mathrm{n}(\%)$ & $198 / 1034(19.1)$ & $151 / 904(16.7)$ & $47 / 130(36.2)$ & $<0.001$ \\
\hline Acute liver injury, $\mathrm{n}(\%)$ & $10 / 1042(1.0)$ & $9 / 911(1.0)$ & $1 / 131(0.8)$ & $>0.99$ \\
\hline Acute kidney injury, $\mathrm{n}(\%)$ & $122 / 1073(11.4)$ & $89 / 940(9.5)$ & $33 / 133(24.8)$ & $<0.001$ \\
\hline Coagulopathy, $\mathrm{n}(\%)$ & $133 / 1043(12.8)$ & $101 / 914(11.1)$ & $32 / 129(24.8)$ & $<0.001$ \\
\hline Hypoproteinemia, $\mathrm{n}(\%)$ & $118 / 1079(10.9)$ & $89 / 942(9.4)$ & $29 / 137(21.2)$ & $<0.001$ \\
\hline Secondary infection, $\mathrm{n}(\%)$ & $107 / 1016(10.5)$ & $89 / 889(10.0)$ & $18 / 127(14.2)$ & 0.153 \\
\hline
\end{tabular}

The $\mathrm{p}$ value was calculated by $\chi^{2}$ test if not indicated. $\mathrm{n}$ indicates cases with available data.

ARDS, acute respiratory distress syndrome; T2DM, type 2 diabetes mellitus. 
Table 3 Clinical features of survivors and non-survivors in patients with COVID-19 with T2DM

\begin{tabular}{|c|c|c|c|}
\hline & Survivor $(\mathrm{n}=89)$ & Non-survivor $(n=49)$ & $P$ value \\
\hline \multicolumn{4}{|l|}{ Pulmonary complications } \\
\hline ARDS, n (\%) & 21/89 (23.06) & 46/49 (93.88) & $<0.001$ \\
\hline \multicolumn{4}{|l|}{ Extrapulmonary complications } \\
\hline Acute cardiac injury, n (\%) & 10/81 (12.35) & $37 / 49(75.51)$ & $<0.001$ \\
\hline Acute liver injury, n (\%) & 0 & $1 / 45(2.22)$ & $0.344^{*}$ \\
\hline Acute kidney injury, n (\%) & $4 / 85(4.71)$ & $29 / 48(60.42)$ & $<0.001$ \\
\hline Coagulopathy, n (\%) & 9/81 (11.11) & 23/48 (47.92) & $<0.001$ \\
\hline Hypoproteinemia, n (\%) & 6/88 (6.82) & 23/49 (46.94) & $<0.001$ \\
\hline Secondary infection, n (\%) & $8 / 85(9.41)$ & $10 / 42(23.81)$ & 0.029 \\
\hline Number of complications, $\mathrm{n}(\%)$ & & & $<0.001^{*}$ \\
\hline $0, \mathrm{n}(\%)$ & 45/76 (59.21) & $1 / 38(2.63)$ & \\
\hline $1, \mathrm{n}(\%)$ & $16 / 76(21.05)$ & 4/38 (10.53) & \\
\hline $2, \mathrm{n}(\%)$ & $13 / 76(17.11)$ & 7/38 (18.42) & \\
\hline $3, \mathrm{n}(\%)$ & $1 / 76(1.32)$ & 11/38 (28.95) & \\
\hline $4, \mathrm{n}(\%)$ & $1 / 76(1.32)$ & 9/38 (23.68) & \\
\hline $5, \mathrm{n}(\%)$ & 0 & $3 / 38(7.89)$ & \\
\hline $6, \mathrm{n}(\%)$ & 0 & $3 / 38(7.89)$ & \\
\hline
\end{tabular}

The $\mathrm{p}$ value was calculated by $\chi^{2}$ test if not indicated. $\mathrm{n}$ indicates cases with available data.

${ }^{*}$ Fisher test.

ARDS, acute respiratory distress syndrome; T2DM, type 2 diabetes mellitus.

was significantly higher in patients with pre-existing T2DM compared with those without T2DM (35.3\% vs $17.4 \%, \mathrm{p}<0.001$ ) (table 2). In the unadjusted Cox model, pre-existing T2DM was associated with increased risk of death (HR 2.00, 95\% CI 1.45 to 2.75 ; $\mathrm{p}<0.001$ ), ARDS (HR $1.63,5 \%$ CI 1.25 to 2.12; p<0.001), ACI (HR 2.43, $95 \%$ CI 1.75 to $3.37 ; \mathrm{p}<0.001$ ), AKI (HR $2.71,95 \%$ CI 1.82 to $4.04 ; \mathrm{p}<0.001$ ), coagulopathy (HR $2.28,95 \%$ CI 1.53 to $3.39 ; \mathrm{p}<0.001$ ), and hypoproteinemia (HR 2.39, 95\% CI 1.57 to $3.63 ; \mathrm{p}<0.001)$. After adjusting for age, gender, comorbidities, and treatments (including antiviral and antibiotic therapy), the HRs for death, ARDS, ACI, AKI, coagulopathy, and hypoproteinemia in preexisting diabetic patients were 1.47 (95\% CI 1.04 to 2.08, $\mathrm{p}=0.028), 1.37$ (95\% CI 1.03 to $1.81, \mathrm{p}=0.029), 1.50(95 \%$ CI 1.05 to 2.15 ), $\mathrm{p}=0.025), 1.76$ (95\% CI 1.14 to 2.71 ), $\mathrm{p}=0.010), 1.58$ (95\% CI 1.03 to $2.44, \mathrm{p}=0.036)$, and 1.92 (95\% CI 1.23 to 3.02, $\mathrm{p}=0.004$ ), respectively (online supplemental table $\mathrm{S} 2$ ).

\section{Coagulopathy was a major extrapulmonary risk factor for} death in inpatients with COVID-19 with pre-existing T2DM

As shown in table 3, in the subgroup of COVID-19 hospitalized patients with pre-existing T2DM, patients who survived had a lower proportion of pulmonary complications (acute respiratory distress syndrome, $23.06 \%$ vs $93.88 \%, \mathrm{p}<0.001)$ and extrapulmonary complications, including ACI $(12.35 \%$ vs $75.51 \%$, p $<0.001)$, AKI $(4.71 \%$ vs $60.42 \%, \mathrm{p}<0.001)$, coagulopathy $(11.11 \%$ vs $47.92 \%$, $\mathrm{p}<0.001)$, hypoproteinemia ( $6.82 \%$ vs $46.94 \%, \mathrm{p}<0.001)$, and secondary infection $(9.41 \%$ vs $23.81 \%, \mathrm{p}<0.001)$ as compared with those who died.

In addition, we performed both univariate and multivariate Cox analyses in hospitalized patients with COVID-19 with or without pre-existing T2DM. ARDS, ACI, ALI, AKI, coagulopathy, d-dimer, hypoproteinemia, secondary infection, antiplatelet therapy, and anticoagulant therapy were included for multivariate Cox analyses in patients without and with pre-existing T2DM (table 4). ARDS (HR 12.18, 95\% CI 5.74 to 25.89; p<0.001) and ACI (HR 4.42, 95\% CI 2.73 to 7.15; $\mathrm{p}<0.001$ ) were significantly associated with death in patients with out T2DM, whereas, after adjustment for ARDS, ACI, ALI, AKI, coagulopathy, d-dimer, hypoproteinemia, secondary infection, antiplatelet therapy, and anticoagulant therapy in the patients with pre-existing T2DM (table 4), ARDS (HR 7.96, 95\% CI 2.25 to 28.24; $\mathrm{p}=0.001$ ) and coagulopathy (HR 2.37, 95\% CI 1.08 to 5.21; $\mathrm{p}=0.032$ ) were significantly associated with death. The Kaplan-Meier survival curve also showed poorer survival in patients with coagulopathy compared with those without in hospitalized patients with COVID-19 with pre-existing T2DM (figure 1). In addition, we have tracked d-dimer changes from admission and made a dynamic analysis between survivors and non-survivors in COVID-19 inpatients with pre-existing T2DM (online supplemental figure S1). The result showed that the d-dimer in inpatients with COVID-19 with T2DM significantly increased in nonsurvivors. These results indicated that coagulopathy was 


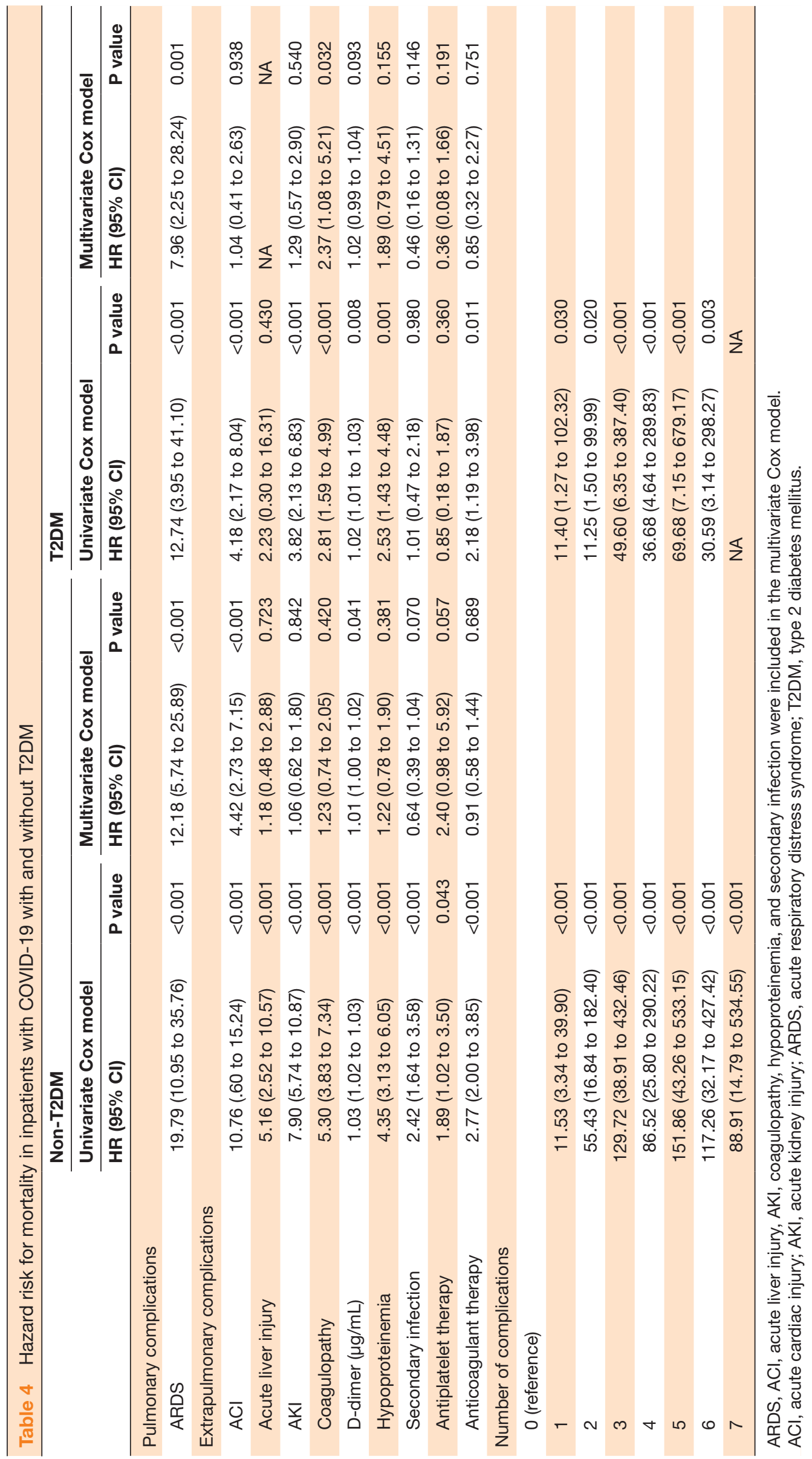




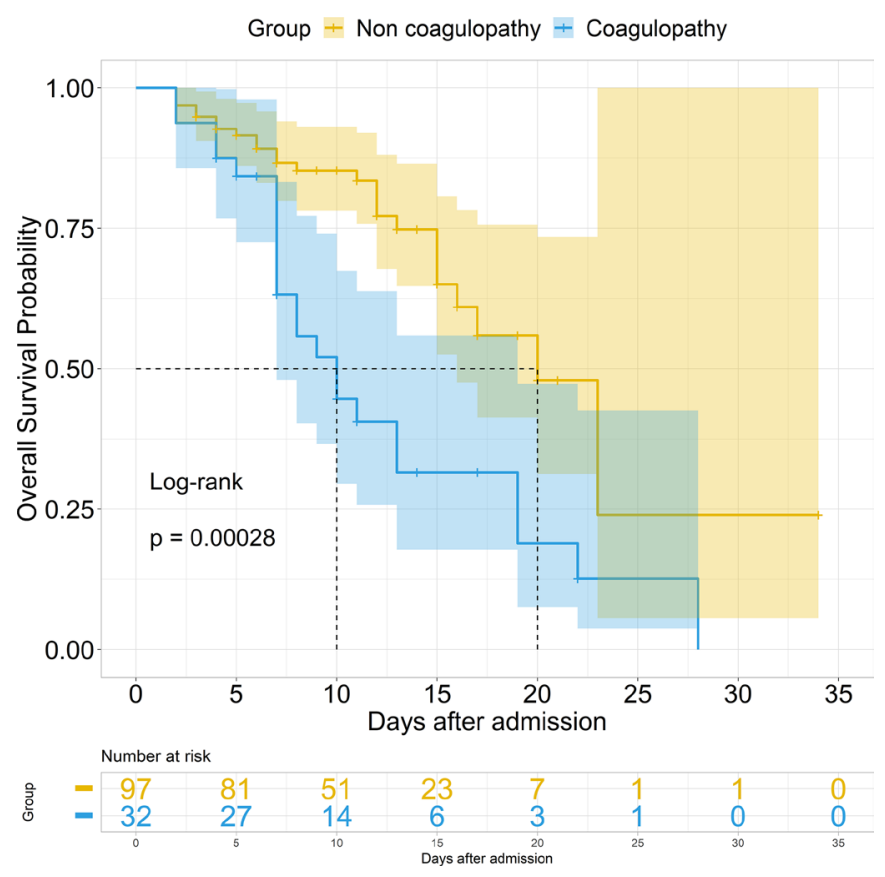

Figure 1 Survival curve in hospitalized patients with COVID-19 with pre-existing T2DM. The survival curve was developed by the Kaplan-Meier method with log-rank test between non-coagulopathy and coagulopathy in hospitalized patients with COVID-19 with pre-existing T2DM. T2DM, type 2 diabetes mellitus.

the major extrapulmonary risk factor for the death in patients with COVID-19 with pre-existing T2DM.

\section{DISCUSSION}

In the current study, we demonstrated that type 2 diabetes, a common comorbidity of COVID-19, was associated with a higher risk of death and multiple organ dysfunctions. Moreover, in hospitalized patients with COVID-19 with T2DM, ARDS and coagulopathy were the main causes of mortality, with HR of 7.96 (95\% CI 2.25 to 28.24, $\mathrm{p}=0.001$ ) for ARDS and HR of 2.37 (95\% CI 1.08 to $5.21, \mathrm{p}=0.032$ ) for coagulopathy. This was different from inpatients with COVID-19 without T2DM, in whom ARDS and cardiac injury were the main causes of mortality, with an HR of 12.18 (95\% CI 5.74 to 25.89, $\mathrm{p}<0.001$ ) for ARDS and an HR of 4.42 (95\% CI 2.73 to 7.15, $\mathrm{p}<0.001$ ) for cardiac injury.

Our study first demonstrated that coagulopathy complication emerged as a key risk factor in hospitalized patients with COVID-19 with type 2 diabetes in addition to pulmonary complication. The SARS-CoV-2 infection caused clusters of pulmonary illness similar to SARS coronavirus infection and ARDS rapidly developed in severe patients. ${ }^{17}$ Not only capable of causing pulmonary illness, COVID-19 may also cause damage to extrapulmonary organs such as the heart, the kidneys, as well as other organ systems such as the blood and the immune system. ${ }^{18}$ Patients with COVID-19 eventually died of ARDS, multiple organ failure, shock, heart failure, arrhythmias, and renal failure. ${ }^{6} 19$ Type 2 diabetes is a common comorbidity and exists in approximately $20 \%$ of hospitalized patients with COVID-19 in Wuhan, China. ${ }^{6}$ Evidence from epidemiological observations showed that the risk of a fatal outcome was $50 \%$ increase in patients with COVID-19 with diabetes compared with those without diabetes. ${ }^{3}$ Notably, care must be taken in interpreting the significant difference in outcomes between patients with COVID-19 with diabetes and those without diabetes. In our study, we demonstrated that ARDS was independently associated with an increased risk of mortality in both patients with diabetes and those without diabetes, which is consistent with previous studies showing that severe respiratory dysfunction was the main cause of coronavirus-induced death. ${ }^{20}$ Moreover, in patients with COVID-19 without diabetes, cardiac injury was independently with an increased risk of mortality. This was also consistent with previous studies reported that patients with COVID-19 with cardiac injury presented with more severe acute illness and a higher risk of mortality during hospitalization. ${ }^{721}$ However, it is notable that coagulopathy rather than cardiac injury was independently associated with an increased risk of mortality in patients with diabetes with COVID-19. In our study, $24.8 \%$ of patients with diabetes developed coagulopathy. This suggested coagulopathy played a critical role in the pathogenesis of SARS-CoV-2-induced death in patients with diabetes.

Type 2 diabetes is a prothrombotic state. Hyperglycemia and chronic hyperinsulinism are the origin of abnormalities in all phases of coagulation, including platelet hyper-reactivity, endothelial dysfunction, impaired fibrinolysis, leukocyte activation, low-grade inflammation, and microparticle involvement. ${ }^{22}{ }^{23}$ In our study, patients with COVID-19 with type 2 diabetes showed elevated d-dimer and prolonged PT. Coagulopathy occurred more frequently in patients with COVID-19 with diabetes than those without diabetes. However, the mechanism of coagulopathy among these patients with COVID-19 remains uncertain. Evidence from case reports elucidated the clinical sequential traits in patients with COVID-19 with diabetes or not. The patient with diabetes and obesity developed progressive respiratory failure and subsequently developed multiorgan failure. Then once mesenteric ischemia occurred, myocardial infarction and circulatory failure subsequently occurred, which led to death. However, in other patients without diabetes, when the mesenteric ischemia occurred, the disease deterioration did not progress so quickly and fatally, and the patient finally survived with small intestine resection. ${ }^{24}$ The reasons for the discrepancy could be attributed to the prothrombotic response, which attempts to prevent diffuse hemorrhage, but instead resulted in overt clot formation with detrimental effects in patient recovery and survival.

SARS-CoV-1 and Middle East Respiratory syndrome presented with thrombotic complications and hematological manifestations. ${ }^{25} 26$ Similarly, coagulopathy has emerged as an important issue in patients with 
COVID-19. SARS-CoV-2 infected the host through the ACE 2 receptor, which was expressed in several organs, including the lung, heart, kidney and intestine, and also expressed by endothelial cells ${ }^{27}$ that facilitated the induction of endotheliitis. The dysfunction of endothelial cells induced by infection resulted in excess thrombin generation and fibrinolysis shutdown, ${ }^{28}{ }^{29}$ which indicated a hypercoagulable state in patients with COVID19. Existence of disseminated intravascular coagulation is common in dying patients with COVID-19. Abnormal coagulation with increased d-dimer, fibrin degradation product and prolonged PT have been found to be associated with poor prognosis in patients infected by the SARS-CoV-2. ${ }^{30}$ Moreover, our study demonstrated coagulopathy was the major extrapulmonary risk factor for death in hospitalized patients with COVID-19 with type 2 diabetes, though cardiac injury was well associated with mortality in hospitalized patients with COVID-19 without type 2 diabetes.

The early application of anticoagulant therapy in severe COVID-19 has been suggested by some expert consensus for improving outcome ${ }^{31}$; however, no specific inclusion or exclusion criteria have been pointed out so far. Tang et al demonstrated the mortality of heparin users were lower than non-users in patients with a sepsisinduced coagulopathy score of $\geq 4$ or d-dimer of $>3.0 \mathrm{ug} /$ $\mathrm{mL}$, and suggested that heparin treatment appears to be associated with better prognosis in patients with severe COVID-19 with coagulopathy. ${ }^{32}$ The findings in our study additionally suggested the need of early application of anticoagulant therapy in the hospitalized patients with COVID-19 with diabetes. However, the type of drug, dosage and optimal duration of anticoagulant therapy need to be elucidated.

Our study also had some limitations. First, due to the retrospective study design, not all laboratory tests were examined in all patients. Therefore, their role might be underestimated as the mediator in the association between diabetes and death in patients with COVID19. Second, this study was conducted in a single-center hospital with limited sample size, and the data regarding body mass index and state of diabetes control were not comprised in this study. Data from a larger population and multiple centers are warranted to further confirm the association of coagulopathy with mortality in patients with COVID-19 with diabetes. Finally, the retrospective design in nature could not elucidate the effect of anticoagulant therapy on better prognosis in patients with COVID-19 with diabetes, because patients were treated with heparin during hospitalization once they had developed coagulopathy or disseminated intravascular coagulation. A well-designed randomized controlled trial could be conducted to explore the effect of early application of anticoagulant therapy.

In conclusion, type 2 diabetes is a common comorbidity among hospitalized patients with COVID-19, and it is associated with a higher risk of in-hospital mortality and pulmonary and extrapulmonary complications.
Specifically, in hospitalized patients with COVID-19 with type 2 diabetes, coagulopathy complication is emerging as a key risk factor of death, in addition to pulmonary complication. Although the exact mechanism still needs to be elucidated, these findings suggest an urgent need to consider anticoagulant therapy in the management of hospitalized patients with COVID-19 with diabetes.

\section{Author affiliations}

${ }^{1}$ Department of Pulmonary and Critical Care Medicine, Zhongshan Hospital, Fudan University, Shanghai, China

${ }^{2}$ Department of Endocrinology and Metabolism, Zhongshan Hospital, Fudan University, Shanghai, China

${ }^{3}$ Department of Pulmonary and Critical Care Medicine, Zhongshan Hospital, Qingpu Branch, Shanghai, China

${ }^{4}$ Tuberculosis and Respiratory Department, Wuhan Jinyintan Hospital, Wuhan, China ${ }^{5}$ Department of Infectious Diseases, Fengxian Guhua Hospital, Shanghai, China

${ }^{6}$ Shanghai Respiratory Research Institute, Shanghai, China

${ }^{7}$ National Clinical Research Center for Aging and Medicine, Huashan Hospital,

Fudan University, Shanghai, China

Correction notice This article has been corrected since it was published. Equal contributorship statement has been updated.

Acknowledgements The authors thank all patients and health providers involved in this study and Yaohui Li (Department of Urology, Zhongshan hospital, Fudan University) for help in the statistical analysis.

Contributors XC and YChen drafted the manuscript. XC, YChen, CW and MW researched the literature. $X C, Y C h e n, Y S$ and $X L$ contributed to the statistical analysis. XC, CW, JX, MW, YChao, YZ, DH, CD and JS collected the epidemiological and clinical data. $X C$ and $Y C h e n$ contributed to editing the manuscript and figure construction. YS conceived and supervised the study. All authors reviewed and approved the final version of the manuscript. YS had full access to all of the data in the study and take responsibility for the integrity of the data and the accuracy of the data analysis. XC, YChen, CW, and MW contributed equally and share first authorship.

Funding This study was supported by the National Natural Science Foundation of China (NSFC) for Novel Coronavirus Pneumonia (82041003, to YS), Prevention and Treatment of Infection in Novel Coronavirus Pneumonia Patients from the Science and Technology Committee of Shanghai Municipality (20411950402, to YS), the Shanghai key discipline of medicine (ZK2019B07 SZ2019-1, to CD), the subspecialist project of Qingpu Branch of Zhongshan Hospital, Fudan University (YZK 2019-04, to CW), Shanghai Municipal Key Clinical Specialty (shslczdzk02201, to YS), Shanghai Top-Priority Clinical Key Disciplines Construction Project (2017ZZ02013, to YS).

Competing interests None declared.

Patient consent for publication Not required.

Ethics approval The study was approved by the ethics committee of Wuhan Jinyintan Hospital (number KY-2020-44.01), and the requirement for informed consent was waived by the ethics boards of the hospital.

Provenance and peer review Not commissioned; externally peer reviewed.

Data availability statement All data relevant to the study are included in the article or uploaded as supplemental information.

Supplemental material This content has been supplied by the author(s). It has not been vetted by BMJ Publishing Group Limited (BMJ) and may not have been peer-reviewed. Any opinions or recommendations discussed are solely those of the author(s) and are not endorsed by BMJ. BMJ disclaims all liability and responsibility arising from any reliance placed on the content. Where the content includes any translated material, BMJ does not warrant the accuracy and reliability of the translations (including but not limited to local regulations, clinical guidelines, terminology, drug names and drug dosages), and is not responsible for any error and/or omissions arising from translation and adaptation or otherwise.

Open access This is an open access article distributed in accordance with the Creative Commons Attribution Non Commercial (CC BY-NC 4.0) license, which permits others to distribute, remix, adapt, build upon this work non-commercially, and license their derivative works on different terms, provided the original work is 
properly cited, appropriate credit is given, any changes made indicated, and the use is non-commercial. See: http://creativecommons.org/licenses/by-nc/4.0/.

\section{ORCID iDs}

Yuye Zhang http://orcid.org/0000-0002-7106-2159

Yuanlin Song http://orcid.org/0000-0002-9826-4383

\section{REFERENCES}

1 World Health Organization. Who coronavirus disease (COVID-19) Dashboard. Available: https://covid19.who.int/ [Accessed 3 Jun 2020].

2 van Vught LA, Wiewel MA, Klein Klouwenberg PMC, et al. Admission hyperglycemia in critically ill sepsis patients: association with outcome and host response. Crit Care Med 2016;44:1338-46.

3 Zhu L, She Z-G, Cheng X, et al. Association of blood glucose control and outcomes in patients with COVID-19 and pre-existing type 2 diabetes. Cell Metab 2020;31:1068-77.

4 Zhu N, Zhang D, Wang W, et al. A novel coronavirus from patients with pneumonia in China, 2019. N Engl J Med 2020;382:727-33.

5 Goh KJ, Choong MC, Cheong EH, et al. Rapid progression to acute respiratory distress syndrome: review of current understanding of critical illness from COVID-19 infection. Ann Acad Med Singap 2020;49:108-18.

6 Chen N, Zhou M, Dong X, et al. Epidemiological and clinical characteristics of 99 cases of 2019 novel coronavirus pneumonia in Wuhan, China: a descriptive study. The Lancet 2020;395:507-13.

7 Shi S, Qin M, Shen B, et al. Association of cardiac injury with mortality in hospitalized patients with COVID-19 in Wuhan, China. JAMA Cardiol 2020;5:802.

8 World Health Organizaiotion. Clinical management of severe acute respiratory infection when Novel coronavirus $(\mathrm{nCoV})$ infection is suspected: interim guidance [article online]. Available: https://www. who.int/publications-detail/clinical-management-of-severe-acuterespiratory-infection-when-novel-coronavirus-(ncov)-infection-issuspected [Accessed 7 May 2020].

9 Wu C, Chen X, Cai Y, et al. Risk factors associated with acute respiratory distress syndrome and death in patients with coronavirus disease 2019 pneumonia in Wuhan, China. JAMA Intern Med 2020;180:934.

10 Chinese Diabetes Society. Guidelines for the prevention and control of type 2 diabetes in China (2017 edition). Zhongguo Shiyong Neike Zazhi 2018;38.

11 Chen T, Wu D, Chen H, et al. Clinical characteristics of 113 deceased patients with coronavirus disease 2019: retrospective study. BMJ 2020:m1091.

12 idney Disease: Improving Global Outcomes (KDIGO) Acute Kidney Injury Work Group. KDIGO clinical practice guideline for acute kidney injury. Kidney Int Suppl 2012;2:1.

13 Shi S, Qin M, Shen B, et al. Association of cardiac injury with mortality in hospitalized patients with COVID-19 in Wuhan, China. JAMA Cardiology 2020;5:802.
14 Zhou F, Yu T, Du R, et al. Clinical course and risk factors for mortality of adult inpatients with COVID-19 in Wuhan, China: a retrospective cohort study. The Lancet 2020;395:1054-62.

15 Garner JS, Jarvis WR, Emori TG, et al. Cdc definitions for nosocomial infections, 1988. Am J Infect Control 1988;16:128-40.

16 Kulcsar KA, Coleman CM, Beck SE, et al. Comorbid diabetes results in immune dysregulation and enhanced disease severity following MERS-CoV infection. JCl Insight 2019;4.

17 Huang C, Wang Y, Li X, et al. Clinical features of patients infected with 2019 novel coronavirus in Wuhan, China. The Lancet 2020;395:497-506.

18 Wang T, Du Z, Zhu F, et al. Comorbidities and multi-organ injuries in the treatment of COVID-19. The Lancet 2020;395:e52.

19 Huang C, Wang Y, Li X, et al. Clinical features of patients infected with 2019 novel coronavirus in Wuhan, China. Lancet 2020;395:497-506

20 Guan W-J, Ni Z-Y, Hu Y, et al. Clinical characteristics of coronavirus disease 2019 in China. N Engl J Med 2020;382:1708-20.

21 Guo T, Fan Y, Chen M, et al. Cardiovascular implications of fatal outcomes of patients with coronavirus disease 2019 (COVID-19). JAMA Cardiol 2020;5:811.

22 Picard F, Adjedj J, Varenne O. [Diabetes Mellitus, a prothrombotic disease]. Ann Cardiol Angeiol 2017;66:385-92.

23 Sobczak AIS, Stewart AJ. Coagulatory defects in type-1 and type-2 diabetes. Int J Mol Sci 2019;20:6345.

24 Varga Z, Flammer AJ, Steiger P, et al. Endothelial cell infection and endotheliitis in COVID-19. The Lancet 2020;395:1417-8.

25 Wong RSM, Wu A, To KF, et al. Haematological manifestations in patients with severe acute respiratory syndrome: retrospective analysis. BMJ 2003;326:1358-62.

26 Assiri A, Al-Tawfiq JA, Al-Rabeeah AA, et al. Epidemiological, demographic, and clinical characteristics of 47 cases of middle East respiratory syndrome coronavirus disease from Saudi Arabia: a descriptive study. Lancet Infect Dis 2013;13:752-61.

27 Ferrario CM, Jessup J, Chappell MC, et al. Effect of angiotensinconverting enzyme inhibition and angiotensin II receptor blockers on cardiac angiotensin-converting enzyme 2. Circulation 2005;111:2605-10.

28 Levi M, van der Poll T. Coagulation and sepsis. Thromb Res 2017;149:38-44.

29 Schmitt FCF, Manolov V, Morgenstern J, et al. Acute fibrinolysis shutdown occurs early in septic shock and is associated with increased morbidity and mortality: results of an observational pilot study. Ann Intensive Care 2019;9:19.

30 Tang N, Li D, Wang X, et al. Abnormal coagulation parameters are associated with poor prognosis in patients with novel coronavirus pneumonia. J Thromb Haemost 2020;18:844-7.

31 Zhai Z, Li C, Chen Y, et al. Prevention and treatment of venous thromboembolism associated with coronavirus disease 2019 infection: a consensus statement before guidelines. Thromb Haemost 2020;120:937-48.

32 Tang N, Bai H, Chen X, et al. Anticoagulant treatment is associated with decreased mortality in severe coronavirus disease 2019 patients with coagulopathy. J Thromb Haemost 2020;18:1094-9. 